\title{
Lung clearance index in subjects with cystic fibrosis in Italy
}

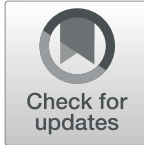

Enrico Lombardi ${ }^{*}$ (D), Simone Gambazza ${ }^{2,3,4}$, Ugo Pradal $^{5}$ and Cesare Braggion ${ }^{1}$

\begin{abstract}
The Lung Clearance Index $(\mathrm{LCl})$ is an index derived from washout recordings, able to detect early peripheral airway damage in subjects with cystic fibrosis (CF) with a greater sensitivity than spirometry.

$\mathrm{LCl}$ is a marker of overall lung ventilation inhomogeneity; in fact, as pulmonary ventilation worsens, the number of tidal breaths and the expiratory volumes required to clear the lungs of a marker gas are increased, as documented by a greater value.

In the field of CF, $\mathrm{LCl}$ allows indirect investigation of the small airways $(<2 \mathrm{~mm})$ the site where, from a pathophysiologic point of view, the disease begins due to the defect of the CF transmembrane-conductance regulator (CFTR) protein. Infant pulmonary function changes seem to occur before clinically overt symptoms of lower respiratory illness occur.

When performing the test, it is important to refer to the American Thoracic Society and European Respiratory

Society consensus statements and apply a strict standardization.

In Italy the first tests were carried out in 2014 for research purpose and now approximately 10 centers are collecting data and are experiencing a consistency in repeating exams.

Currently in Italian centers children at pre-school age are the main target: in this population it is important to have a sensitive and feasible test, non-invasive, that can be performed at tidal volume without sedation, and requiring minimal cooperation and coordination, and that can be used longitudinally over time. Another target could be the transplanted subjects to detect early signs of lung function decline.

The content of this paper captures the experience and discussions among some of the Italian centers where $\mathrm{LCl}$ is currently used for research and/or in clinical practice about the method and the need to have a common approach.

The aim of this paper is not to describe the methodology of MBW, but to inform the pediatric community about the possible application of $\mathrm{LCl}$ in CF.
\end{abstract}

Keywords: LCl, Cystic fibrosis, MBW, Ventilation inhomogeneity, Preschool, Children, Lung function

\section{Introduction}

The multiple breath washout test (MBW) has been used for long time to measure static lung volumes during tidal breathing, with minimal cooperation and coordination needs. Recently the lung clearance index (LCI), an index derived from washout recordings, has proven to be able to detect early peripheral damages in subjects with cystic fibrosis (CF) with a greater sensitivity than

\footnotetext{
* Correspondence: enrico.lombardi@meyer.it

${ }^{1}$ Azienda Ospedaliero-Universitaria Meyer, Pediatric University Hospital, Viale

Pieraccini 24, 50139 Florence, Italy

Full list of author information is available at the end of the article
}

conventional spirometry. This is a potential big opportunity for research and ultimately for clinical use.

The content of this paper captures the experience and discussions about the method and the need to have a common approach among some of the main Italian centers where LCI is currently used for research and/or in clinical practice.

The aim of this paper is not to describe the methodology of MBW, but to inform the pediatric community about the possible applications of LCI in CF, while many papers about the standardization are currently available in the literature.

(c) The Author(s). 2019 Open Access This article is distributed under the terms of the Creative Commons Attribution 4.0 International License (http://creativecommons.org/licenses/by/4.0/), which permits unrestricted use, distribution, and 


\section{Lung clearance index: state of the art}

The measurement of lung volume using inert gas dilution was reported first in the 1940s [1, 2]. The first respiratory mass spectrometer device was developed in 1952 [3] but the modern era of respiratory gas chromatography began in 1971 [4]. Initially MBW devices used $4 \%$ sulfur hexafluoride $\left(\mathrm{SF}_{6}\right)$ as inert gas, but at present this concentration of the gas is generally no longer utilized, mostly because of concerns regarding greenhouse gas emissions and costs. Nitrogen wash-out devices measuring gas concentration via molar mass have been used since $1985[5,6]$. For main stream molar mass inert gas concentration calculation, temperature and humidity corrections are necessary [7]. Different devices show similar performance in terms of discrimination power and reproducibility, but they cannot be considered as interchangeable [8]. Current data have not indicated any ethnic differences [9].

MBW devices measure how many lung volume turnovers (usually 6-7) are needed to wash out traces of an inert gas from the lungs. In the case of exogenous inert gases $\left(\mathrm{SF}_{6}, \mathrm{He}\right)$, the gas is released at a known concentration during the wash-in phase and the wash-in is complete when the expired gas concentration reaches the concentration of the gas supplied. On the contrary, no formal wash-in phase is required for nitrogen and few tidal breaths are carried out to ensure that the concentration of $\mathrm{N}_{2}$ is stable (normally $80 \%$ ); during the washout phase, the subjects inhale gases that do not contain the tracer gas (room air for $\mathrm{SF}_{6}$ devices and $100 \%$ oxygen for $\mathrm{N}_{2}$ devices). The washout is interrupted once the tracer gas concentration reaches 1/40th of its starting concentration in 3 consecutive breaths $[10,11]$.

$\mathrm{LCI}$ is a marker of overall lung ventilation inhomogeneity; in fact, as pulmonary ventilation worsens, the number of tidal breaths and the expiratory volumes required to clear the lungs of the marker gas are increased, as documented by a greater LCI value [12].

Over the past 15 years, the application of LCI in CF has become widespread. In the field of CF, LCI allows indirect investigation of the small airways $(<2 \mathrm{~mm})$; the site where, from a pathophysiologic point of view, the disease begins.

\section{Cystic fibrosis}

Unlike the conducting airways, where mucosal biofilm is removed by ciliary movements, in the smaller airways the liquid must be reabsorbed, otherwise the exchange is hindered. The defect of CFTR (cystic fibrosis transmembrane-conductance regulator) protein explains the damage at the early stage of cystic fibrosis disease: the protein is expressed in the airway surface epithelium, that loses its absorption capacity, and in the subcutaneous glands, that secrete an altered mucus obstructing the glandular ducts $[13,14]$. In addition, the $\mathrm{pH}$ of the membrane is affected by the impaired exchange of chloride and bicarbonate with serious consequences on innate immunity [13].

CF leads to obstructive clinical presentations, with ventilation inhomogeneity (VI), heterogeneous flow-volume loops and uneven topographic damage distribution [15].

Lung disease remains the main cause of morbidity and mortality in patients with CF therefore it would be crucial to assess early intervention strategies, before clinical symptoms become apparent, through suitable and sensitive tools.

Several instrumental approaches are available today to detect lung damage in the early stages of the disease.

Examination of broncho-alveolar lavage (BAL) in children under 2 years of age may detect positivity for Staphylococcus aureus, Pseudomonas aeruginosa as well as neutrophils and elastase positivity, thus testifying that infection and inflammation begin early [16]. Detected at 3 months of age, elastase positivity in BAL proved to be an air trapping and bronchiectasis risk indicator as confirmed by CT and MRI in the following 3 years [16].

Even forced (thoracic and abdominal) FEVs may detect early signs of the disease [17]. Further diagnostic tools include electrical impedance tomography [18] and Helium MRI [19], an index of inhomogeneous perfusion [20-22], which may provide further information as compared to MBW, where non-ventilated regions do not contribute to the inhomogeneity shown by MBW [23].

Infant pulmonary function changes seem to occur before clinically overt symptoms of lower respiratory illness occur [24]; in fact, structural changes in small airways start shortly after birth in CF, they accumulate over time and subsequently reach a certain functional threshold quantifiable using MBW. LCI has proved able to detect early lung injury in CF in a large longitudinal study [25]. Moreover, LCI showed to be indicative for the presence or absence of structural lung changes after 3 years in $87 \%$ of cases in a prospective, longitudinal study [26].

Spirometry is conventionally used in the assessment of $\mathrm{CF}$ lung disease, however $\mathrm{FEV}_{1}$ can remain within normal limits throughout childhood. LCI requires only passive co-operation and it is able to identify inhomogeneous ventilation in children with normal spirometry [27]; moreover, it is much more sensitive but less specific than $\mathrm{FEV}_{1}$ [28]. LCI discriminates infants with CF versus healthy subjects and it gains more sensitivity if it is considered together with $\mathrm{FEV}_{1}$ [29]. Abnormal LCI values in the preschool age range are stronger predictors than preschool $\mathrm{FEV}_{1}$ of subsequent abnormal school age $\mathrm{FEV}_{1}$ [30]. LCI can be considered as a test performed at rest that predicts some abnormalities appearing at exercise in CF children with normal spirometry as well [31]. 
Furthermore, baseline LCI allows predicting pulmonary exacerbations in young patients with CF with the increase of $1 \mathrm{z}$-score resulting in $12 \%$ increase in the number of exacerbations/year and correlates with the respiratory domain score at the CFQ-R (cystic fibrosis questionnaire-revised), a validated patient-reported outcome, even in the subgroup with normal $\mathrm{FEV}_{1}$ [32].

According to the experiences collected so far, LCI positioning is in mild pulmonary disease, for early changes detection and possibly for disease evolution monitoring, considering that the examination must be performed on lungs that are still functioning.

LCI within-subject variability is low and this strengthens the use of LCI to monitor lung disease progression in CF patients. An increase in LCI > 17\% compared to previous LCI-measurement in clinically stable $\mathrm{CF}$ patients may therefore indicate early lung disease progression [33].

Furthermore, in the small group of patients with clinical and CT evidence of lung damage only in late adolescence or adult age, LCI may play a role as well: in particular when the result of $\mathrm{FEV}_{1}$ is within the lower limit of normal (LLN) [34] and/or there are no reductions of $\mathrm{FEF}_{25}$ (forced expiratory flow at $25 \%$ of $\mathrm{FVC}$ ). It can be clearly stated that LCI cannot be used alone as an index of the severity of disease and doesn't give any further information in grading the severity of obstruction. At this aim, conventional spirometry, in particular $\mathrm{FEV}_{1}$ should be considered as the reference.

Sensitive outcome measures to assess the efficacy of therapeutic interventions in patients with CF play a great role. LCI, but not spirometry was able to detect a treatment effect from hypertonic saline inhalation in patients with CF with mild disease [35]. Moreover, LCI is an indicator of improvement after intra venous antibiotic treatment and the higher the LCI value is at the beginning of the study the more it decreases after treatment [36].

LCI has proven to be a more effective and sensitive alternative than $\mathrm{FEV}_{1}$ to assess response to treatment with Ivacaftor in patients with CF who have the G551D-CFTR mutation and reduced lung function, but still normal spirometry [37]. Using z-scores to adjust for the known growth (i.e. height)-related decline in LCI during early childhood [38] increases the validity of results in evaluating treatment effects [24].

LCI has been also suggested as a surrogate for chest computed tomography to detect structural lung abnormalities in preschool and school age children with $\mathrm{CF}$, however it cannot replace chest imaging using computed tomography to screen for bronchiectasis in this population [39].

A systematic review of the clinimetric properties of LCI demonstrates its reliability, validity and responsiveness coupled to an attractive feasibility profile [40]. Eventually LCI can be used for research purposes because smaller sample sizes are required compared to $\mathrm{FEV}_{1}$, which requires large samplings and long observation periods [41].

\section{Technical aspects in pediatric patients with CF}

In recent years, the statements and guidelines of the international scientific societies about the use of tests like LCI have increased [10, 11, 42, 43].

Several MBW devices for LCI measure in children and adults [44] have been compared, but a deep analysis of different devices goes beyond the purpose of this paper. Exhalyzer $^{\circ} \mathrm{D}$ is the device chosen by the European Cystic Fibrosis Society [8] and the one most frequently used in Italy. However, several software are available for analyses of MBW indices [45].

Hereinafter we are not going to describe in depth the technical aspects of MBW; for this purpose, it is important to refer to the American Thoracic Society and European Respiratory Society consensus statements when performing the test, for preschool age patients, a specific document has recently been published [43], for children and adults the 2013 guidelines should be followed [11].

The preschool subject should be tested in seated position breathing at a tidal volume through a mouthpiece or a mask closely adhering to the face (Fig.1). The tracer gas (helium, argon, or sulfur hexafluoride) is first washed in then washed out; alternatively, $100 \%$ oxygen can be inhaled to wash out the resident nitrogen from the lungs, without a wash-in phase.

There are many variables that need to be taken into account when performing the test:

- the stability of clinical condition

- the administration of bronchodilator therapy

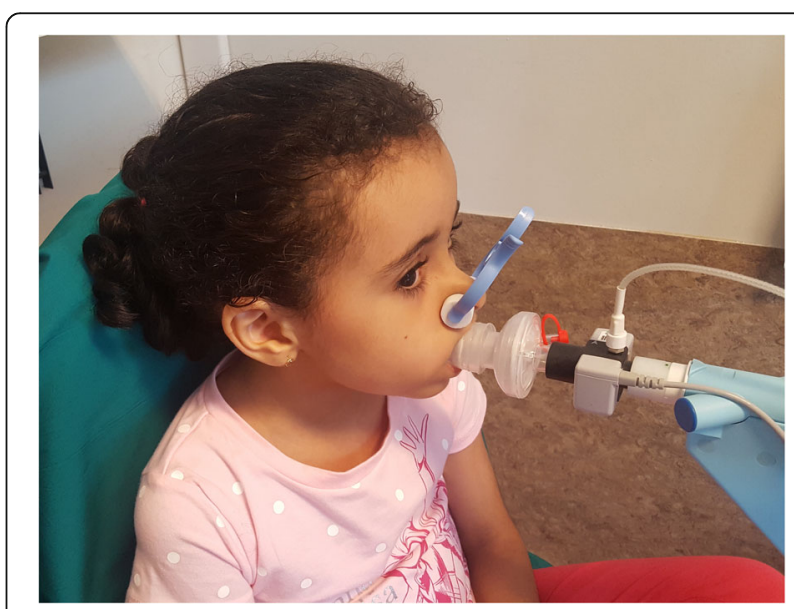

Fig. 1 Measurement conditions. Preschool girl performing MBW while seating and breathing at tidal volume through the mouthpiece and a bacterial filter (permission to publication obtained) 
- the possible execution of physiotherapy before examination, that can modify airway obstruction and ventilation inhomogeneity

- equipment calibration (depending on temperature, etc.)

- the stability of the wall mounted gas-system

In order to standardize all technical variables, it would be desirable to use the standard kit and all other materials provided by the manufacturer.

Criteria for technical acceptability are reported in the ERS/ATS Consensus [11] but there are several aspects that require adaptation to the preschool age [46]. The environment for preschool MBW testing should be as child-friendly as possible and distraction during the assessment must be enough to take the child's attention away from his/her breathing. LCI success rates are 76$90 \%$ in infants during quiet natural sleep $[47,48]$ or with sedation [49].

In preschoolers, the use of a facemask, sealed with putty, and video distraction, achieves success rates of nearly $80 \%$, though varying with age: $50 \%$ in $2-3$ years old rising to $87 \%$ of 5-6 years old [50]. Similarly, LCI variability improves with age to a within-test $\mathrm{CV}$ (coefficient of variation) of $5.2 \%$ in preschoolers [50]. In a clinical study, it was possible to perform LCI examination in $90 \%$ of cases in the $4-16$ age group, while 2 or more measurements were performed in $41 \%$ of cases [51].

According to the ERS/ATS consensus statement [43] at least three acceptable MBW trials whenever possible should be collected, however, in pre-school children data reported from only two acceptable trials provide comparable outcomes, ability to discriminate between health and disease, and associations with clinical markers of CF lung disease, improving feasibility in young children participating in longitudinal assessments and clinical trials [52].

LCI also requires some time to be performed, because repeated measurements may take several times to ensure reliable results. The reported average duration of a $\mathrm{N}_{2}$-MBW test in children with cystic fibrosis is $3.3 \mathrm{~min}$ (1.2 to 6.4), while it is $2.9 \mathrm{~min}(1.2-4.0)$ in controls [51].

The cross-contamination between patients can be minimized by cleaning and using disposable inserts [53] and following specific CF guidelines on infection prevention and control [54].LCI tests with different end-points (e.g. 1/30th, 1/20th or 1/10th of the initial concentration of tracer gas, or using a fixed washout period, for example $20 \mathrm{~s}$, or a fixed number of breaths) have been studied to save time in performing the test [55].

Reference values depend on the age of subjects, the type of device available, and the type of software used. Depending on the choice of gas, MBW indices differ substantially [44], for example, because helium is much lighter than Sulphur hexafluoride it generates higher LCI values [11].
Considering the age of subjects and factors such as gas, equipment, dead space, software, LCI is usually below 8.5 lung turnovers in healthy subjects [45]. Other relevant factors influencing MBW measures, are the posture during tests (supine or seated) [56], as well as sedation.

Reference values are not interchangeable [40] and few data for MBW measurements across different age groups are available [57].

LCI is thought to be independent of age, but recent evidences suggest that in the first 5 years of life LCI decreases in a nonlinear pattern as height increases; therefore, the use of fixed upper limit of normal (ULN) is not appropriate for children $<6 \mathrm{yr}$. [38].

The different algorithms used in the available software package to calculate LCI values could explain some false normal values in CF patients, highlighting the need for meticulous standardization not only of procedures but also of software algorithms [58].

\section{The Italian scenario}

Eight centers are currently using LCI in Italy. The first tests were carried out in 2014 for research purpose and now some centers are collecting data and are experiencing a consistency in repeating exams, provided that they apply a strict standardization.

\section{Indications}

Pulmonary function tests play a key role in the management of CF in Italian centers, in children over 6 years of age. However, several matters hinder the same efficacy in the assessment of younger children and infants.

LCI looks as an attractive opportunity, because it is a sensitive, non-invasive and feasible test, particularly in the preschool age target when minimal cooperation and coordination are required during the test at tidal volume.

Currently, there is no sufficient evidence to recommend inclusion of LCI into the routine diagnostic evaluation and clinical monitoring of patients with $\mathrm{CF}$, as stated by the Cystic Fibrosis Foundation in 2015 [42], but LCI may be considered as a tool to evaluate ongoing symptoms or monitor response to treatment, and as a measure in clinical research studies [41].

The primary use of LCI is to study CF patients of all ages without clinical or functional evidence of lung impairment to evaluate whether subtle lung disease is present. Currently the main target of LCI in Italian centers are children of preschool age. Children under 6 years of age have a developing respiratory system and a constantly evolving respiratory physiology, they experience frequent clinical episodes that may result in severe damage. Within this age group a particular subgroup is represented by children aged 2 to 6 years: they are too old to be sedated, but too young to actively cooperate 
[10]. In this age group spirometric parameters such as mid-expiratory flows $\left(\mathrm{FEF}_{25}, \mathrm{FEF}_{50}\right.$ or $\left.\mathrm{FEF}_{75}\right)$ are not reliable. Therefore, it is important in the preschool group to have a sensitive test, to be performed without sedation, at tidal volume, and to be used longitudinally over time. Although it is a non-invasive test, LCI can be time-consuming and requires dedicated staff, therefore the recommended frequency should be every 6 months under clinical stable conditions.

Furthermore, in transplanted subjects it is crucial to detect early signs of lung function decline and LCI, performed at an increased frequency, can be used for early medical referral.

In these scopes of LCI, preschool children and transplanted subjects, a prospective data collection is needed to acquire a greater experience in measurement and maximize the advantages.

\section{Interpretation of results}

The LCI results are clearly influenced by biological variability and should be interpreted within the clinical history of the patient, taking into account many physiological variables and technical issues. Up to now, LCI calculated as 1/40th of starting end-tidal concentration of $\mathrm{N}_{2}$ (LCI 2.5\%) is the most robust output of the $\mathrm{N}_{2}-\mathrm{MBW}$ test; the validity of its shortened version, i.e. LCI $5 \%$, that is $1 / 20$ th of starting end-tidal concentration of $\mathrm{N}_{2}$, has not reached a consensus yet.

Table 1 shows three different $\mathrm{N}_{2}$-MBW reports, as available with Exhalyzer ${ }^{\circ} \mathrm{D}$. The means and coefficient of variation $(\mathrm{CV} \%)$ of three test results are displayed.
Subjects A and B completed three reproducible runs, defined as a variation of FRC and LCI 2.5 values within $10 \%$. Subject C performed a poor technically acceptable test, with an FRC CV\% above 15\% and therefore results were not considered valid.

The first subject (A) is a 32 year-old man with CF, without pancreatic insufficiency and with normal pulmonary function ( $\mathrm{FEV}_{1}$ equals to $95.1 \%$ predicted); LCI was 7.15 thus confirming an optimal respiratory functionality. Subject B is a boy with CF aged 5 years old, with an impaired pancreatic function. Classical spirometry was not available due to the young age, and therefore LCI was used as a mean of respiratory surveillance. Unfortunately, LCI was above the considered normality cut-off, describing an early lung disease otherwise not detectable. This information forced the CF team to further investigations. No conclusions could be drawn for subject $C$.

The understanding of other alternatives to LCI as outcomes of the $\mathrm{N}_{2}$-MBW test, such as the phase III analysis of the expirogram, i.e. Scond and Sacin, or moment ratios, i.e. $\mathrm{M} 1 / \mathrm{M} 0$ or $\mathrm{M} 2 / \mathrm{M} 0$, is beyond the scope of this report.

Interpretation and management of LCI results differ among centers. In order to manage the informative content of LCI tests, it might be useful to measure other parameters together with LCI, such as those coming from spirometry, when available, or from lung imaging, integrating the results from a clinical point of view, keeping in mind that different parameters are measuring different elements: some structural, some functional.

Table 1 Standard $\mathrm{N}_{2}$-Multiple Breath Washout reporting available in Italian CF centers

\begin{tabular}{lcccccc}
\hline & \multicolumn{2}{c}{ Subject A } & \multicolumn{2}{c}{ Subject B } & \multicolumn{2}{c}{ Subject C } \\
\cline { 2 - 6 } FRC [I] & Results & CV\% & Results & CV\% & Results & CV\% \\
LCI 2.5\% norm & 2.582 & 1.7 & 0.792 & 1.6 & 1.135 & 16 \\
LCI 5\% norm & 7.15 & 3.9 & 9 & 5.7 & 9.6 & 9.7 \\
M1/M0 & 5.27 & 3.3 & 6.14 & 8.3 & 6.46 & 2.6 \\
M2/M0 & 1.73 & 3.3 & 2.02 & 3.5 & 2.18 & 6.8 \\
Scond*VT & 6.26 & 6.7 & 9.07 & 9.9 & 10.58 & 15 \\
Sacin*VT & 0.014 & 80.7 & 0.06 & 46.1 & 0.064 & 36.5 \\
RQ & 0.06 & 21.9 & 0.154 & 87.2 & 0.145 & 43.2 \\
VT/FRC & 1.16 & 1.8 & 1.38 & 13.1 & 1.07 & 12.2 \\
VT/mean [ml] & 0.466 & 8.7 & 0.237 & 5.3 & 0.274 & 9.4 \\
VdCO [ml] & 1205 & 9.2 & 188 & 3.8 & 308 & 9.8 \\
CEV [I] & 158 & 4.6 & 41 & 26.9 & 54 & 6.8 \\
\hline
\end{tabular}

$\mathrm{CV}=$ coefficient of variation; functional residual capacity; LCI $2.5 \%$ norm = normalized lung clearance Index at $2.5 \%$; LCl $5 \%$ norm = normalized lung clearance index at 5\%; $\mathrm{M} 1 / \mathrm{MO}=$ moment ratio: non-uniform alveolar flow volume distribution; $\mathrm{M} 2 / \mathrm{M} 0$ = moment ratio: lung regions that empty late during the washout; Scond ${ }^{*} \mathrm{VT}=$ convection-dependent inhomogeneity corrected for tidal volume; Sacin ${ }^{*} \mathrm{VT}=$ diffusion-convection-dependent inhomogeneity corrected for tidal volume; $\mathrm{RQ}=$ respiratory quotient; $\mathrm{VT}=$ tidal volume; $\mathrm{VdCO} 2$ = volume of gas coming from dead space; $\mathrm{CEV}=$ cumulative expired volume 
MRI indices strongly correlated with LCI, as well as $\mathrm{FEV}_{1}$ [59]; on the other hand, LCI, but not body plethysmography, is associated with air trapping detected by CT scan [60].

LCI has been reported to be a useful marker to track early disease progression and based on the results of LCI more accurate decisions as the indication of other diagnostic tests, their early execution vs routine planned management and, last but not least, it may serve as a tool to guide therapies in young patients with CF [61, 62].

It should be highlighted that a good part of literature data has been obtained with $\mathrm{SF}_{6}$ and mass spectrometry, expensive equipment used in a few laboratories; therefore, there is the unmet need for new data to be acquired with the recently introduced instruments in children.

Health care professionals involved in LCI measurements are aware that a gold standard is unavailable, different methods have different reference values, different specificity and sensibility. In the Italian centers the limits of the exam are well-known, and so is the demand for working together in order to finalize a common behavior.

Recent studies have advanced our understanding of the role of the LCI in clinical practice: LCI is a promising surveillance tool to monitor early structural CF lung disease in preschool and school-age children although its exact clinical utility is still uncertain [63].

\section{Conclusions}

LCI can bring added value to the evaluation of the patient's clinical status. It is difficult to quantify this extra-informative content as it is extremely variable depending on the characteristics of each patient. It can be affirmed that the exam should be performed in the right patient to obtain meaningful data and to demonstrate its full value. Furthermore, LCI results should always be considered in the framework of symptoms, signs and other clinical exams to monitor disease severity over time and evaluate response to treatment.

In the preschool children group MBW test appears to provide the greatest discrimination, among the available lung functional tests, between children with $\mathrm{CF}$ and healthy control subjects, due to the regionally heterogeneous nature of early airway obstruction.

In Italy, time is probably ripe to create a specific LCI working group focusing on developing collaborative projects. A priority should be the implementation of a common data collection tool to minimize the differences among centers and obtain comparable tests. Device-specific reference values for preschool Italian children are also urgently needed.

\section{Abbreviations}

ATS: American Thoracic Society; BAL: Bronchoalveolar Lavage; CF: Cystic Fibrosis; CFTR: Cystic fibrosis transmembrane-conductance regulator; CT: Computed tomography; ERS: European Respiratory Society; LCl: Lung Clearance Index; LLN: Lower Limit of Normal; MBW: Multiple Breath Wash out; MRI: Magnetic Resonance Imaging; MS: Mass spectrometry; SF 6 : Sulfur hexafluoride

\section{Acknowledgements}

Vertex Pharmaceuticals Incorporated was given the opportunity to review this manuscript for factual accuracy at the request of the authors. The authors retained final decision-making with regards to the content.

\section{Funding}

Editorial coordination and support were provided by Norbert Brunhuber, Vertex Pharmaceuticals. Medical writing assistance and publication process were provided under the direction of the authors by Maura llardi at BOTO and editorial assistance was provided by Michael Friedman at Excerpta Medica, which were both supported by Vertex Pharmaceuticals.

\section{Availability of data and materials}

Not applicable.

\section{Authors' contributions}

All authors made substantial contributions to conception and design of the manuscript. EL has prepared the draft of the manuscript, SG has provided the technical figure. All authors have revised the manuscript critically and have given final approval of the version to be published. All authors agreed to be accountable for all aspects of the work in ensuring that questions related to the accuracy or integrity of any part of the work are appropriately investigated and resolved.

\section{Ethics approval and consent to participate}

Not applicable.

\section{Consent for publication}

Not applicable.

\section{Competing interests}

EL has received fees or travel grants during the past 5 years from Angelini, Boehringer, Chiesi, GSK, Lusofarmaco, Novartis, Omron, Vertex Pharmaceuticals and Vifor; SG reports personal fees from Vertex Pharmaceuticals; CB and UP declare that they have no competing interests.

\section{Publisher's Note}

Springer Nature remains neutral with regard to jurisdictional claims in published maps and institutional affiliations.

\section{Author details \\ ${ }^{1}$ Azienda Ospedaliero-Universitaria Meyer, Pediatric University Hospital, Viale Pieraccini 24, 50139 Florence, Italy. 'Fondazione IRCCS Ca' Granda Ospedale Maggiore Policlinico, Cystic Fibrosis Centre, Milan, Italy. ${ }^{3}$ Department of Clinical Sciences and Community Health, Università degli Studi di Milano, Milan, Italy. ${ }^{4}$ Fondazione IRCCS Ca' Granda Ospedale Maggiore Policlinico, U.O.C. Direzione delle Professioni Sanitarie, Milan, Italy. ${ }^{5}$ UO Pediatria Ospedale di Rovereto, APSS Trento, Trento, Italy.}

Received: 19 October 2018 Accepted: 16 April 2019

Published online: 02 May 2019

\section{References}

1. Darling RC, Cournand A, Richards DW. Studies on the intrapulmonary mixture of gases. III. An open circuit method for measuring residual air. J Clin Invest. 1940;19:609-18.

2. Meneely GR, Kaltreider NL. The volume of the lung determined by helium dilution. Description of the method and comparison with other procedures. J Clin Invest. 1949;28:129-39.

3. Becklake MR. A new index of the intrapulmonary mixture of inspired air. Thorax. 1952;7:111-6. 
4. Pauling L, Robinson AB, Teranishi R, Cary P. Quantitative analysis of urine vapor and breath by gas-liquid partition chromatography. Proc Natl Acad Sci U S A. 1971;68:2374-6.

5. Wall MA. Moment analysis of multibreath nitrogen washout in young children. J Appl Physiol. 1985;59:274-9.

6. Kraemer $\mathrm{R}$, Meister $\mathrm{B}$. Fast real-time moment-ratio analysis of multibreath nitrogen washout in children. J Appl Physiol. 1985;59:1137-44.

7. Latzin P, Sauteur L, Thamrin C, Schibler A, Baldwin D, Hutten GJ, et al. Optimized temperature and deadspace correction improve analysis of multiple breath washout measurements by ultrasonic flowmeter in infants. Pediatr Pulmonol. 2007:42:888-97.

8. Jensen R, Stanojevic S, Gibney K, Salazar JG, Gustafsson P, Subbarao P, et al. Multiple breath nitrogen washout: a feasible alternative to mass spectrometry. PLoS One. 2013;8:e56868.

9. Sonnappa S, Bastardo CM, Wade A, Bush A, Stocks J, Aurora P. Repeatability and bronchodilator reversibility of lung function in young children. Eur Respir J. 2013:42:116-24.

10. Beydon N, Davis SD, Lombardi E, Allen JL, Arets HGM, Aurora P, et al. An official American Thoracic Society/European Respiratory Society statement: pulmonary function testing in preschool children. Am J Respir Crit Care Med. 2007;175:1304-45.

11. Robinson PD, Latzin P, Verbanck S, Hall GL, Horsley A, Gappa M, et al. Consensus statement for inert gas washout measurement using multipleand single- breath tests. Eur Respir J. 2013;41:507-22.

12. Rosenfeld M, Allen J, Arets BHGM, Aurora P, Beydon N, Calogero C, et al. An official American Thoracic Society workshop report: optimal lung function tests for monitoring cystic fibrosis, bronchopulmonary dysplasia, and recurrent wheezing in children less than 6 years of age. Ann Am Thorac Soc. 2013;10:S1-11.

13. Saint-Criq V, Gray MA. Role of CFTR in epithelial physiology. Cell Mol Life Sci. 2017;74:93-115.

14. Rowe SM, Miller S, Sorscher EJ. Cystic fibrosis. N Engl J Med. 2005;352:1992-2001.

15. Mellins RB, Levin OR, Ingram RH, Fishman AP. Obstructive disease of the airways in cystic fibrosis. Pediatrics. 1968:41(3):560-73.

16. Sly PD, Gangell CL, Chen L, Ware RS, Ranganathan S, Mott LS, et al. Risk factors for bronchiectasis in children with cystic fibrosis. N Engl J Med. 2013; 368:1963-70.

17. Kozlowska WJ, Bush A, Wade A, Aurora P, Carr SB, Castle RA, et al. Lung function from infancy to the preschool years after clinical diagnosis of cystic fibrosis. Am J Respir Crit Care Med. 2008;178:42-9.

18. Zhao Z, Müller-Lisse U, Frerichs I, Fischer R, Möller K. Regional airway obstruction in cystic fibrosis determined by electrical impedance tomography in comparison with high resolution CT. Physiol Meas. 2013;34(11):N107-14.

19. Altes TA, Johnson M, Fidler M, Botfield M, Tustison NJ, Leiva-Salinas C, et al. Use of hyperpolarized helium-3 MRI to assess response to ivacaftor treatment in patients with cystic fibrosis. J Cyst Fibros. 2017;16:267-74.

20. Wielpütz MO, Eichinger M, Biederer J, Wege S, Stahl M, Sommerburg O, et al. Imaging of cystic fibrosis lung disease and clinical interpretation. Rofo. 2016:188:834-45

21. Stahl M, Wielpütz MO, Graeber SY, Joachim C, Sommerburg O, Kauczor H-U, et al. Comparison of lung clearance index and magnetic resonance imaging for assessment of lung disease in children with cystic fibrosis. Am J Respir Crit Care Med 2016;rccm.201604-08930C.

22. Wielpütz MO, Puderbach M, Kopp-Schneider A, Stahl M, Fritzsching E, Sommerburg $\mathrm{O}$, et al. Magnetic resonance imaging detects changes in structure and perfusion, and response to therapy in early cystic fibrosis lung disease. Am J Respir Crit Care Med. 2014;189:956-65.

23. Marshall H, Horsley A, Taylor CJ, Smith L, Hughes D, Horn FC, et al. Detection of early subclinical lung disease in children with cystic fibrosis by lung ventilation imaging with hyperpolarised gas MRI. Thorax. 2017;72:1147-50.

24. Subbarao P, Stanojevic S, Brown M, Jensen R, Rosenfeld M, Davis S, et al Lung clearance index as an outcome measure for clinical trials in young children with cystic fibrosis. A pilot study using inhaled hypertonic saline. Am J Respir Crit Care Med. 2013;188:456-60

25. Kraemer R, Blum A, Schibler A, Ammann RA, Gallati S. Ventilation inhomogeneities in relation to standard lung function in patients with cystic fibrosis. Am J Respir Crit Care Med. 2005;171:371-8.

26. Fuchs SI, Gappa M, Eder J, Unsinn KM, Steinkamp G, Ellemunter H. Tracking lung clearance index and chest $C T$ in mild cystic fibrosis lung disease over a period of three years. Respir Med. 2014;108:865-74.
27. Gustafsson PM, Aurora P, Lindblad A. Evaluation of ventilation maldistribution as an early indicator of lung disease in children with cystic fibrosis. Eur Respir J. 2003;22:972-9.

28. Gustafsson PM, De Jong PA, Tiddens HAWM, Lindblad A. Multiple-breath inert gas washout and spirometry versus structural lung disease in cystic fibrosis. Thorax. 2008:63:129-34.

29. Hoo A-F, Thia LP, Nguyen TTD, Bush A, Chudleigh J, Lum S, et al. Lung function is abnormal in 3-month-old infants with cystic fibrosis diagnosed by newborn screening. Thorax. 2012;67:874-81.

30. Aurora P, Stanojevic S, Wade A, Oliver C, Kozlowska W, Lum S, et al. Lung clearance index at 4 years predicts subsequent lung function in children with cystic fibrosis. Am J Respir Crit Care Med. 2011;183:752-8.

31. Chelabi R, Soumagne T, Guillien A, Puyraveau M, Degano B. In cystic fibrosis, lung clearance index is sensitive to detecting abnormalities appearing at exercise in children with normal spirometry. Respir Physiol Neurobiol. 2018;247:9-11.

32. Vermeulen F, Proesmans M, Boon M, Havermans T, De Boeck K. Lung clearance index predicts pulmonary exacerbations in young patients with cystic fibrosis. Thorax. 2014;69:39-45.

33. Svedberg M, Gustafsson PM, Robinson PD, Rosberg M, Lindblad A. Variability of lung clearance index in clinically stable cystic fibrosis lung disease in school age children. J Cyst Fibros. 2018;17:236-41.

34. Quanjer PH, Stanojevic S, Cole TJ, Baur X, Hall GL, Culver BH, et al. Multiethnic reference values for spirometry for the 3-95-yr age range: the global lung function 2012 equations. Eur Respir J. 2012;40:1324-43.

35. Amin R, Subbarao P, Jabar A, Balkovec $S$, Jensen R, Kerrigan S, et al. Hypertonic saline improves the $\mathrm{LCl}$ in paediatric patients with CF with normal lung function. Thorax. 2010;65:379-83.

36. Sonneveld N, Stanojevic S, Amin R, Aurora P, Davies J, Elborn JS, et al. Lung clearance index in cystic fibrosis subjects treated for pulmonary exacerbations. Eur Respir J. 2015;46:1055-64.

37. Davies J, Sheridan H, Bell N, Cunningham S, Davis SD, Elborn JS, et al. Assessment of clinical response to ivacaftor with lung clearance index in cystic fibrosis patients with a G551D- CFTR mutation and preserved spirometry: a randomised controlled trial. Lancet Respir Med. 2013;1:630-8.

38. Lum S, Stocks J, Stanojevic S, Wade A, Robinson P, Gustafsson P, et al. Age and height dependence of lung clearance index and functional residual capacity. Eur Respir J. 2013:41:1371-7.

39. Ramsey KA, Rosenow T, Turkovic L, Skoric B, Banton G, Adams A-M, et al. Lung clearance index and structural lung disease on computed tomography in early cystic fibrosis. Am J Respir Crit Care Med. 2016;193:60-7.

40. Kent L, Reix P, Innes JA, Zielen S, Le Bourgeois M, Braggion C, et al. Lung clearance index: evidence for use in clinical trials in cystic fibrosis. J Cyst Fibros. 2014:13:123-38.

41. Stanojevic S, Ratjen F. Physiologic endpoints for clinical studies for cystic fibrosis. J Cyst Fibros. 2016:15:416-23.

42. Subbarao P, Milla C, Aurora P, Davies JC, Davis SD, Hall GL, et al. Multiplebreath washout as a lung function test in cystic fibrosis. A Cystic Fibrosis Foundation workshop report. Ann Am Thorac Soc. 2015;12:932-9.

43. Robinson PD, Latzin P, Ramsey KA, Stanojevic S, Aurora P, Davis SD, et al. Preschool multiple-breath washout testing. An official American Thoracic Society technical statement. Am J Respir Crit Care Med. 2018;197:e1-19.

44. Poncin W, Singer F, Aubriot A-S, Lebecque P. Agreement between multiplebreath nitrogen washout systems in children and adults. J Cyst Fibros. 2017;16:258-66.

45. Usemann J, Yammine S, Singer F, Latzin P. Inert gas washout: background and application in various lung diseases. Swiss Med Wkly. 2017;147(3334):w14483.

46. Robinson PD, Lum S, Moore C, Hardaker KM, Benseler N, Aurora P, et al. Comparison of facemask and mouthpiece interfaces for multiple breath washout measurements. J Cyst Fibros. 2018;17:511-7.

47. Hülskamp G, Lum S, Stocks J, Wade A, Hoo AF, Costeloe K, et al. Association of prematurity, lung disease and body size with lung volume and ventilation inhomogeneity in unsedated neonates: a multicentre study. Thorax. 2009;64:240-5

48. Latzin P, Roth S, Thamrin C, Hutten GJ, Pramana I, Kuehni CE, et al. Lung volume, breathing pattern and ventilation inhomogeneity in preterm and term infants. PLoS One. 2009:4:e4635.

49. Lum S, Gustafsson P, Ljungberg H, Hulskamp G, Bush A, Carr SB, et al. Early detection of cystic fibrosis lung disease: multiple-breath washout versus raised volume tests. Thorax. 2007;62:341-7. 
50. Aurora P, Bush A, Gustafsson P, Oliver C, Wallis C, Price J, et al. Multiplebreath washout as a marker of lung disease in preschool children with cystic fibrosis. Am J Respir Crit Care Med. 2005;171:249-56.

51. Singer $F$, Kieninger $E$, Abbas $C$, Yammine $S$, Fuchs $O$, Proietti $E$, et al. Practicability of nitrogen multiple-breath washout measurements in a pediatric cystic fibrosis outpatient setting. Pediatr Pulmonol. 2013;48:739-46.

52. Foong RE, Harper AJ, Skoric B, King L, Turkovic L, Davis M, et al. The clinical utility of lung clearance index in early cystic fibrosis lung disease is not impacted by the number of multiple-breath washout trials. ERJ Open Res. 2018;4:00094-2017.

53. Fuchs SI, Gappa M, Waltner-Romen M, Ellemunter H. Hygienic safety of an ultrasonic flow sensor for multiple breath washout. Pediatr Pulmonol. 2009:44:99-100.

54. Saiman L, Siegel JD, LiPuma JJ, Brown RF, Bryson EA, Chambers MJ, et al. Infection prevention and control guideline for cystic fibrosis: 2013 update. Infect Control Hosp Epidemiol. 2014;35:S1-67.

55. Ahmad F, Irving S, Alton E, Davies JC, Macleod K, Rosenthal M, et al. Multiple breath washouts in children can be shortened without compromising quality. Eur Respir J. 2015;46:1814-6.

56. Ramsey KA, McGirr C, Stick SM, Hall GL, Simpson SJ, AREST CF. Effect of posture on lung ventilation distribution and associations with structure in children with cystic fibrosis. J Cyst Fibros. 2017;16:713-8.

57. Fuchs $O$, Latzin $P$, Thamrin $C$, Stern $G$, Frischknecht $P$, Singer $F$, et al. Normative data for lung function and exhaled nitric oxide in unsedated healthy infants. Eur Respir J. 2011;37:1208-16.

58. Anagnostopoulou P, Yammine S, Schmidt A, Korten I, Kieninger E, Mack I, et al. False normal lung clearance index in infants with cystic fibrosis due to software algorithms. Pediatr Pulmonol. 2015;50:970-7.

59. Smith LJ, Collier GJ, Marshall H, Hughes PJC, Biancardi AM, Wildman M, et al. Patterns of regional lung physiology in cystic fibrosis using ventilation magnetic resonance imaging and multiple-breath washout. Eur Respir J. 2018;52:1800821.

60. Rosenow T, Ramsey K, Turkovic L, Murray CP, Mok LC, Hall GL, et al. Air trapping in early cystic fibrosis lung disease-does $C T$ tell the full story? Pediatr Pulmonol. 2017;52:1150-6.

61. Stanojevic S, Davis SD, Retsch-Bogart G, Webster H, Davis M, Johnson RC, et al. Progression of lung disease in preschool patients with cystic fibrosis. Am J Respir Crit Care Med. 2017;195:1216-25.

62. Rayment JH, Stanojevic S, Davis SD, Retsch-Bogart G, Ratjen F. Lung clearance index to monitor treatment response in pulmonary exacerbations in preschool children with cystic fibrosis. Thorax. 2018;73:451-8.

63. Perrem L, Rayment JH, Ratjen F. The lung clearance index as a monitoring tool in cystic fibrosis. Curr Opin Pulm Med. 2018;24:579-85.

Ready to submit your research? Choose BMC and benefit from:

- fast, convenient online submission

- thorough peer review by experienced researchers in your field

- rapid publication on acceptance

- support for research data, including large and complex data types

- gold Open Access which fosters wider collaboration and increased citations

- maximum visibility for your research: over $100 \mathrm{M}$ website views per year

At $\mathrm{BMC}$, research is always in progress.

Learn more biomedcentral.com/submissions 